\title{
LEUCOPHANACEAE, NOVA FAMÍLIA DE BRYOPHYTA PARA O PARÁ, BRASIL
}

\author{
Regina C. L. Lisboa ${ }^{1}$ \\ Maria Josiane L. de Lima ${ }^{1}$
}

Recebido em 18/12/96. Aceito em 15/7/97

\begin{abstract}
RESUMO - (Leucophanaceae, nova família de Bryophyta para o Pará, Brasil). A ocorrência de Leucophanaceae, representada nos neotrópicos pela espécie Leucophanes molleri C. Müll., é registrada no estado do Pará. No Brasil, a espécie apresenta distribuição disjunta, sendo encontrada apenas nas regiões norte e sudeste. A morfologia de L. molleri é apresentada, baseada em fotomicrografias.
\end{abstract}

Palavras-chave: Leucophanaceae, Leucophanes, Bryophyta, disjunção, Pará

\begin{abstract}
Leucophanaceae, a new family of Bryophyta to Pará, Brazil). The ocurrence of Leucophanaceae, represented in the Neotropic by Leucophanes molleri C. Müll., is presented. The disjunct distribution of the specie in the Brazil, where was collected in the north and southeast regions, it is emphasized. Also is presented the morphology of $L$. molleri, with photomicrographs.
\end{abstract}

Key words: Leucophanaceae, Leucophanes, Bryophyta, disjunct distribution, state of Pará

\section{Introdução}

A família Leucophanaceae (Cardot) Fleischer está constituída por um único gênero, Leucophanes, com 12 espécies reconhecidas por Salazar-Allen em sua revisão do gênero para o mundo, em 1986 (Salazar-Allen 1993). É pantropical, com distribuição nas regiões tropicais e subtropicais do velho e novo mundo, nos continentes Asiático, Americano e Oceania, de acordo com Salazar-Allen (1993). Nos Neotrópicos, incluindo o Brasil, essa família está representada pela espécie Leucophanes molleri C. Müll. As espécies L. brasiliense Broth. e L. calymperatum C. Müll., colocadas em sinonímia de L. molleri por Salazar-Allen (1986), seguido por Schäfer-Verwimp (1992), haviam sido anteriormente referidas por Yano (1982), para os Estados do Amazonas, Rondônia e

\footnotetext{
'Departamento de Botânica, Museu Paraense Emílio Goeldi, C.P.399, CEP 66.040-170, Belém, PA, Brasil
} 
Roraima. Até aquela data, essa espécie havia sido referida apenas para o Estado de São Paulo, proveniente de uma coleta realizada em 1901 por Schiffner. Schäfer-Verwimp (1992) a referiu novamente para São Paulo, com base em um material coletado em 1991, ressaltando que o longo período de tempo decorrido após a coleta anterior, exatos 90 anos, havia levado Yano (1975) a supor que a espécie havia desaparecido daquele Estado, em função do desmatamento e aumento da poluição.

Neste trabalho, Leucophanaceae, representada por L. molleri, é referida pela primeira vez para o Estado do Pará, ocorrendo no município de Anajás, na Ilha de Marajó.

\section{Material e métodos}

O material botânico foi coletado e identificado durante o desenvolvimento de um trabalho sobre as briófitas do município de Anajás, em continuação a trabalhos anteriores realizados na Ilha de Marajó (Lisboa et. al. 1993; Lisboa \& Maciel 1994). (1993).

A bibliografia utilizada para identificação foi Yano (1982) e Salazar-Allen

As fotomicrografias foram tiradas em microscópio binocular Nikon, com câmara fotográfica acoplada, a partir de lâminas semi-permanentes, preparadas com solução aquosa de glicerina a $30 \%$ e vedadas com esmalte incolor.

Todas as amostras estudadas foram incorporadas ao Herbário do Museu Paraense Emílio Goeldi (MG).

\section{Resultados e discussão}

Leucophanaceae, representada nos Neotrópicos pela espécie Leucophanes molleri C. Müll., foi coletada pela primeira vez no Estado do Pará, no município de Anajás, localizado centralmente na Ilha de Marajó, $00^{\circ} 59^{\prime} 21^{\prime \prime} \mathrm{S}, 49^{\circ} 56$ ' 24 " W. Caracteriza-se pelo aspecto esbranquiçado, muito semelhante ao da família Leucobryaceae, da qual, segundo Salazar-Allen (1993), foi desmembrada por Fleischer, em 1904, baseado nos caracteres do perístoma. Mas outros autores, como Brotherus (1909, 1924), colocaram Leucophanes em subcategorias (tribos ou subfamílias) de Leucobryaceae, o que foi seguido pela maioria dos especialistas. Edwards (1980) reconsiderou a sugestão de Fleischer, recriando a família Leucophanaceae. Por sua vez, Vitt (1984) colocou Leucophanes em Calymperaceae.

Salazar-Allen (1993), considerando as estruturas do filídio e do perístoma, recoloca Leucophanes em família própria. Neste mesmo trabalho, Salazar-Allen, além do histórico da família e do gênero, descreve e ilustra muito bem $L$. molleri, destacando que a estrutura do filídio, formada por uma faixa central de estereídios (costa) rodeada por camadas de clorocistos e leucocistos, é a característica mais representativa da família. A região basal apresenta lâmina hialina, com uma ou duas células de espessura. 
Leucophanes molleri C. Müll., Flora 69: 285. 1886. (Fig. 1-16).

Espécie-tipo: África, Molleri s. $n$.

Descrição e ilustração: Yano (1982), como Leucophanes brasiliense Broth. e L. calymperatum C. Müll. e Salazar-Allen (1993).

Material examinado: BRASIL, Estado do Pará, Ilha de Marajó, município de Anajás, rio Mocoões, vegetação de várzea, sobre árvore viva, associada a Octoblepharum pulvinatum (Dozy \& Molk.) Mitt., II/94, U. N. Maciel 2199 (MG); idem, asso-ciada a O . pulvinatum e Vesicularia vesicularis (Schwaegr.) var. rutilans (Brid.) Buck, II/94, U. N. Maciel 2210 (MG); idem, sobre cipó vivo, associada a Syrrhopodon incompletus Schwaegr. var. incompletus, $O$. pulvinatume Calymperes erosum C. Müll., II/94, U. N. Maciel 2256 e 2257 (MG).

Comentários: Espécie variável quanto ao tamanho do gametófito, que pode alcançar até $40 \mathrm{~mm}$ de altura, quanto ao ápice do filídio e forma das gemas. O ápice do filídio pode ser acuminado, largamente agudo, obtuso-arredondado, truncado e entalhado (Fig. 9-11). Estas variações do ápice do filídio podem ser encontradas em um mesmo gametófito. As gemas podem ser papilosas, fusiformes, clavadas (Fig. 8), elípticas ou finamente ovaladas, ramificadas ou não na base e com o número de células variáveis (Salazar-Allen 1993).

A variabilidade da espécie certamente contribuiu para o elevado número (oito) de sinonímias, relacionadas em Salazar-Allen (1993). Entretanto, alguns caracteres são relativamente constantes:

- filídio estreitamente lanceolado, apresentando em seção transversal uma única camada de leucocistos (células esbranquiçadas) nos lados ventral e dorsal de uma camada central de clorocistos (células verdes, clorofiladas) (Fig. 1), - costa estreita, percurrente, sulcada, coberta por células hialinas na metade superior do filídio (Fig. 12 e 13), - margens do filídio serreadas no ápice, bordeadas por 2-4 fileiras de células estreitas, alongadas e espessas (estereídios) (Fig. 9 e 14), — presença de 2-3 células vermelho-acastanhadas no filídio, no ponto de inserção ao caulídio (Fig. 15).

Todos os materiais estudados não continham esporófitos, o que já era esperado, uma vez que gametófitos masculinos e esporófitos ainda não foram encontrados nas populações Neotropicais da espécie, de acordo com Salazar-Allen (1993), que descreve os esporófitos a partir de material coletado na África.

No Brasil, a espécie ocorre nos Estados do Amazonas, Rondônia, Roraima e São Paulo, sendo esta a primeira referência para o Estado do Pará. Observa-se um caso de disjunção muito ampla. Todos os espécimes examinados neste trabalho foram coletados sobre caules e/ou raízes de plantas vivas, sempre associados a outras espécies de musgos, discriminadas no material examinado. 


\section{Agradecimentos}

As autoras agradecem ao professor Ubirajara Nery Maciel, pesquisador aposentado, que realizou todas as coletas do material examinado.

\section{Referências bibliográficas}

Brotherus, V. F. 1909. Leucobryaceae. In A. Engler \& K. Prantl (eds.), Die naturlichen Pflanzenfamilien. 1(3): 342 - 351 .

Brotherus, V. F. 1924. Musci (Laubmoose) III. Unterklasse Bryales. In A. Engler \& K. Prantl (eds.), Die naturlichen Pflanzenfamilien 10: 132-478.

Edwards, S. R. 1980. A revision of the west tropical African Calymperaceae. Journal of Bryology 11: 4993.

Lisboa, P. L. B.; Lisboa, R. C. L.; Rosa, N. de A. \& Santos, M. R. dos. 1993. Padrões de diversidade florística na Reserva Ecológica do Bacurizal, em Salvaterra, Illha de Marajó, Pará. Boletim do Museu Paraense Emílio Goeldi, sér. Bot. 9 (2), 223 - 248.

Lisboa, R. C. L. \& Maciel, U. N. 1994. Musgos da Ilha de Marajó-I. Afuá. Boletim do Museu Paraense Emílio Goeldi, sér. Bot. 10 (1) 43 - 55.

Salazar-Allen, N. 1993. Leucophanaceae. Flora Neotropica 59: 1 - 11.

Schäfer-Verwimp, A. 1992. New or interesting records of Brazilian Bryophytes, III. Journal of the Hattori Botanical Laboratory 71: $55-68$.

Vitt, D. H. 1984. Classification of the Bryopsida. In R. M. Schuster, (ed.), New Manual of Bryology 2: 696-759.

Yano, O. 1975. Leucobryaceae (Musci) do Estado de São Paulo. São Paulo: Escola Paulista de Medicina. Dissertação de Mestrado.

Yano, O. 1982. Ocorrência de Leucophanes (Leucobryaceae, Bryopsida) na Amazônia brasileira. Amazoniana 7(3): 349354. 


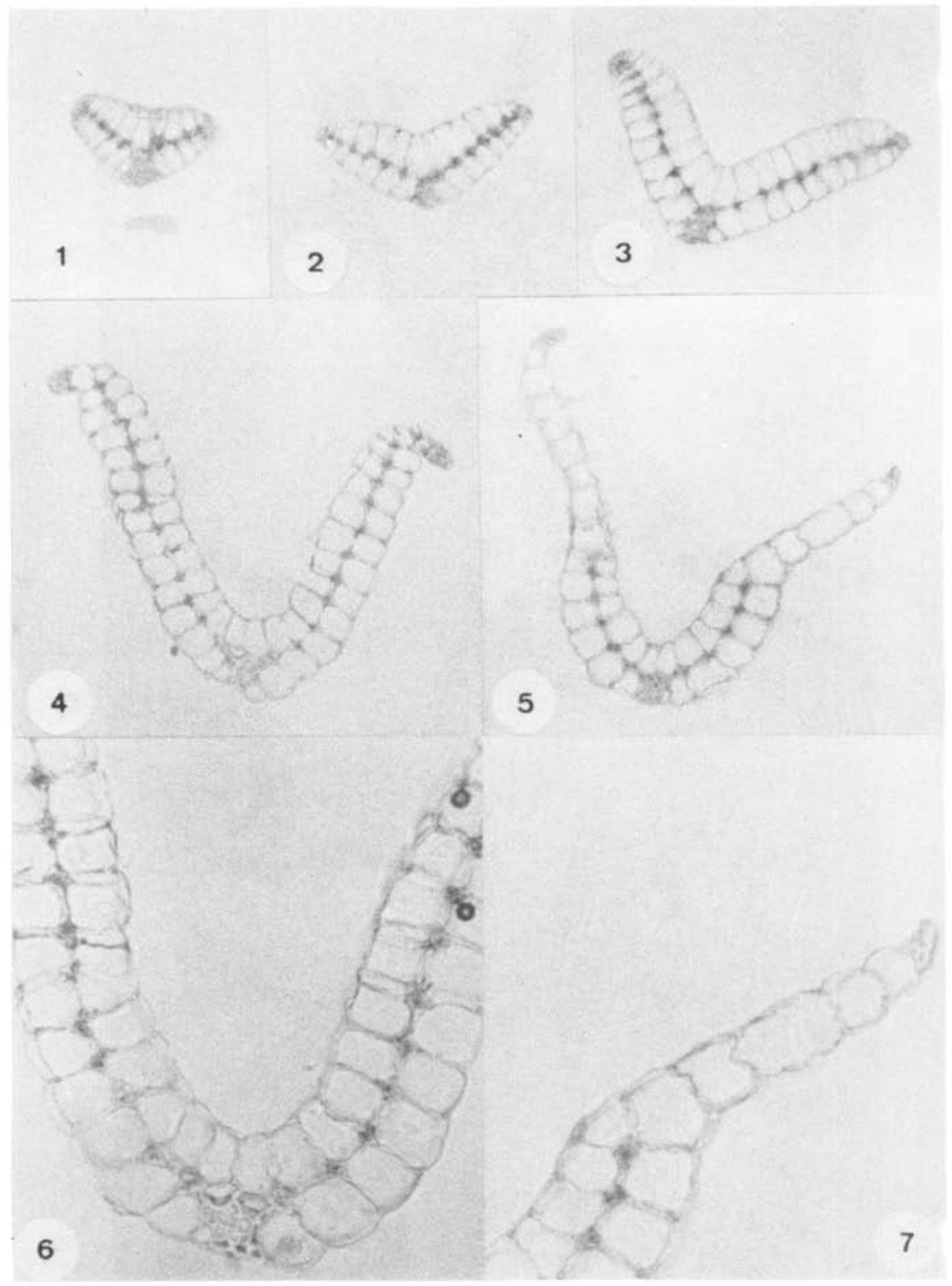

Figura 1-7. Leucophanes molleri C. Müll. 1 - 3: seção transversal do ápice do filídio, em diferentes níveis, $183 \mathrm{X} ; 4$ : seção transversal da região mediana do filídio, $183 \mathrm{X} ; 5$ : seção transversal da região basal do filídio, $183 \mathrm{X} ; 6$ : detalhe da seção em D, destacando estereídios da costa, $366 \mathrm{X}$; 7: detalhe da região basal, estereídios na margem, 366 X (U.N. Maciel 2257). 


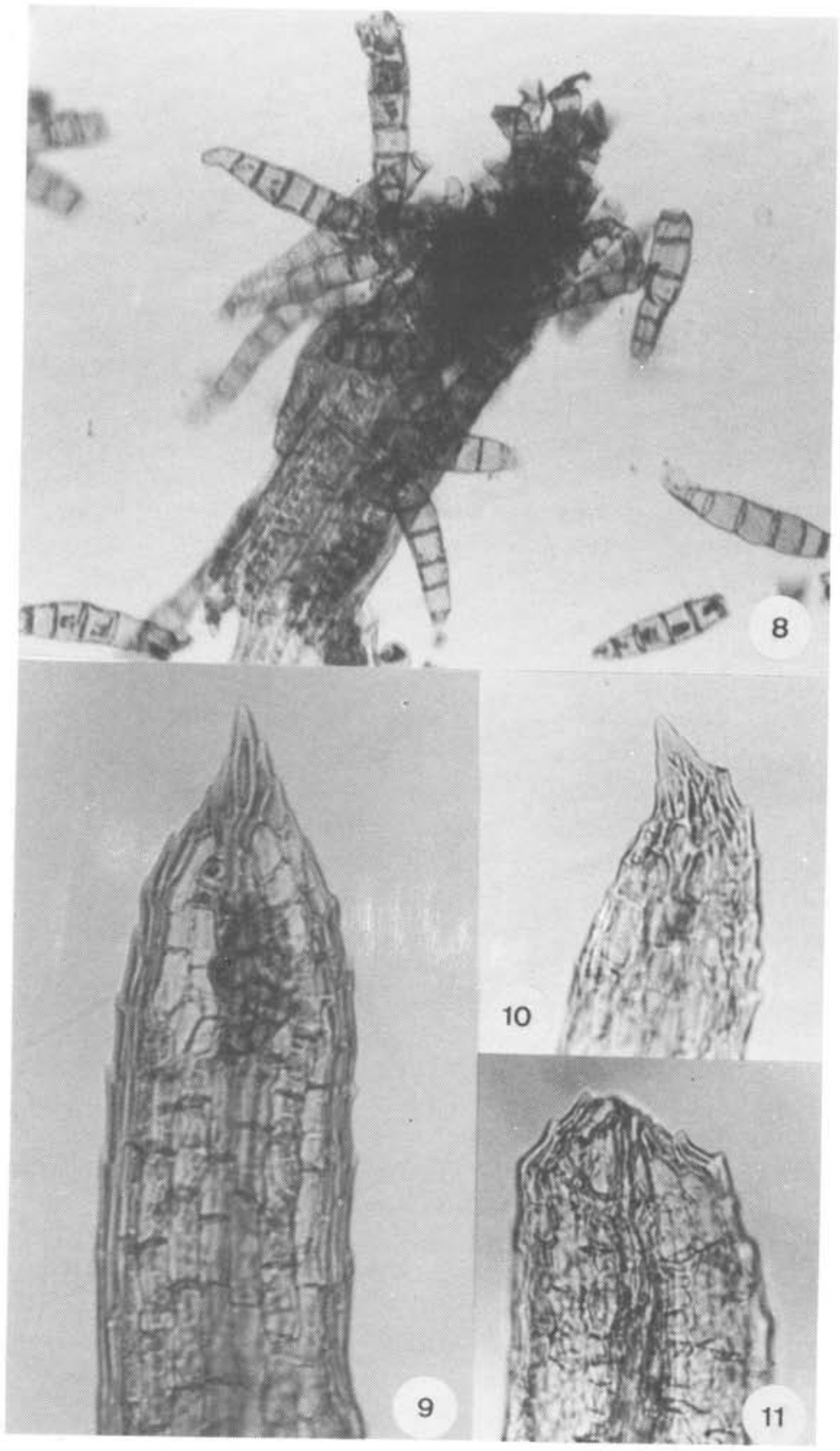

Figura 8-11. Leucophanes molleri C. Müll. 8: gemas no ápice do filídio, 183X; 9: ápice agudo, sem gemas, $366 \mathrm{X}$; 10: ápice agudo-inclinado do filídio, $183 \mathrm{X}$; 11: detalhe do ápice entalhado, $366 \mathrm{X}(U . N$. Maciel 2257). 


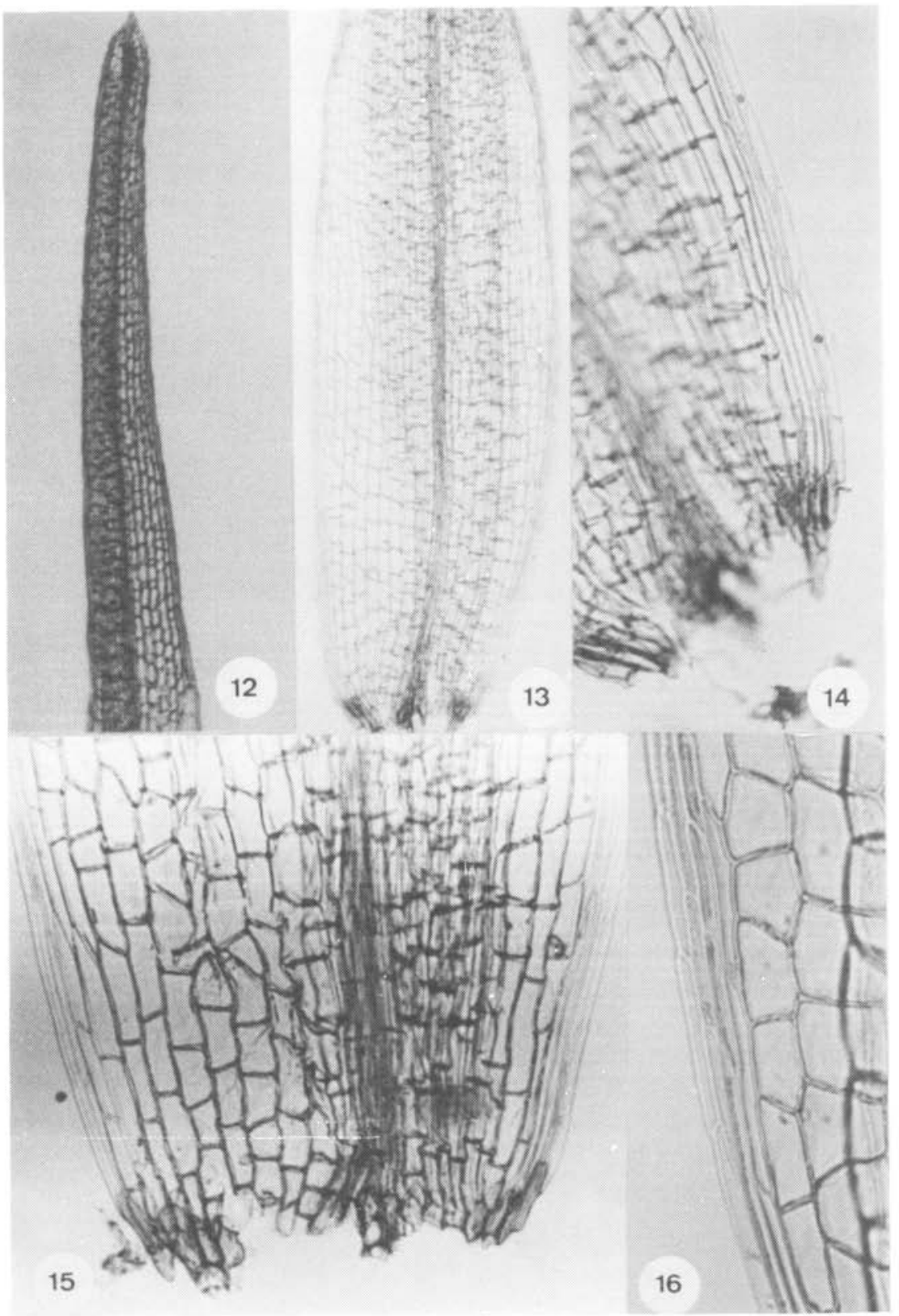

Figura 12-16.Leucophanes molleri C. Müll. 12: região apical e mediana do filídio, $70 \mathrm{X} ; 13$ : região inferior, evidenciando a lâmina hialina basal e a lâmina biestratosa, afinando para a base, 73 X; 14 : detalhe da base, com margem de células estreitas e alongadas, $183 \mathrm{X}$; 15: região basal do filídio, destacando as células de inserção mais escuras, 183 X; 16: detalhe da margem na região basal do filídio, 366 X (U. N. Maciel 2257). 